Teaching \& Learning (2018/2019), 12(1), 72-94

\title{
A Meta-Synthesis on the Application of Gamification in the Higher Education Co- Curricular Environment
}

\author{
LAURA MAMMONE \\ Nipissing University \\ NANCY MAYNES \\ Nipissing University
}

\begin{abstract}
This study sought to examine the existing research on gamification to see whether or not there was the potential for application in the higher education co-curricular environment. This study also aimed to explore the current best practices of gamification in order to define a consistent structure to create a gamified initiative. This meta-synthesis concluded that, due to the lack of consistent gamification structures and the large range of game mechanics and dynamics being utilized in various studies, it is difficult to determine whether gamification has been successful or not in the current educational climates where it has been tested. Through the creation of a recommended structure of gamification to be applied in a volunteer co-curricular environment, future testing can be applied to validate approaches.
\end{abstract}

\section{Introduction}

When we enter today's classrooms, electronic devices are present in many applications and even very young students seem to be very savvy with technology and able to use many forms of technology to support their learning. In Jane McGonigal's (2011) book, Reality is Broken, she introduced a comparison between intrinsic motivation and personal development because of game play versus the real world. According to McGonigal:

The real world just doesn't offer up as easily the carefully designed pleasures, the thrilling challenges, and the powerful social bonding afforded by virtual environments.

Reality doesn't motivate us as effectively. Reality isn't engineered to maximize our potential. (p. 2)

The focus of this paper is learning about what makes games so impactful, and more specifically how is it that they excite and readily engage us. The context of the application of gamification in this study relates to co-curricular programs and events in higher education 
environments. Through examination of concepts related to successful gamification, trends and best practices are explored with the hope of applying findings to the design and implementation of a university student ambassador program to support students' engagement in co-curricular programs that could enrich their student experiences.

\section{Overview of Gamification}

At its most simplistic level, gamification uses the design techniques of games, and places them in non-traditional gaming scenarios that can be used for a variety of purposes such as training, increasing engagement, and for the retention of information. Dominguez et. al. (2013) state that:

...the general purpose of gamification as a way of organizing collaboration is to extract game elements that make good games enjoyable and fun to play, adapt them and use those elements in the given contexts, with the desired outcome being game-like sensations of fun and engagement even if these contexts are normally prone to more banal or boring experiences. (p. 382)

\section{History of Gamification}

Gamification has been in existence beginning as early as the 1970 s with the work of Richard Bartle and Roy Trubshaw (Werbach, 2013). Werbach (2013) discussed how Trubshaw and Bartle created the multi-user dungeon, otherwise known as 'MUD', in 1978. This application is known as the first multi-player online game. Additionally, researcher Tom Malone completed work in 1980 on early video games and demonstrated that children were able to learn from these video games. In 2003, James Paul Gee also wrote about how game designers encode powerful knowledge mechanisms that reflect how people learn (Werbach, 2013). One such gaming project was The Serious Games Movement that began in America, in approximately 2002, through the 'America's Army' initiative, which brought together communities in the military, academia, and private sectors for different non-game purposes such as training and employee engagement.

Werbach (2013) also described Nick Pelling's consulting firm (Conundra) that was established in 2003. Although the company was not highly successful, it was the first example of 
a commercial application that demonstrated that games could be applied to consumer products as well.

Nowadays, gamification is important to study as many large business companies are beginning to adopt this practice into their corporate environments. Some examples of existing companies incorporating gamification include: Microsoft's Fantasy Sales Team, Nike's online community for Nike+, Samsung Nation, Dell World, Foot Locker's Horse with Harden, McDonald's Monopoly, and Verizon Insider. These initiatives use gamification to motivate users to increase usage of their services by offering programs that encourage audience participation in unique and fun ways.

In 2010, gamification began a sharp rise in use due to champions of this concept such as Jesse Schell and Jane McGonigal. Jesse Schell is the CEO of Schell Games and is an example of someone who has much experience sharing his visions of the future of gamification's application to real life through his publication, The Art of Game Design (Schell, 2008). As the former chairman of the International Game Developers' Association, Schell (2008) shared many insights into game design, specifically in classrooms and as personal development tools, and he addressed how to achieve balance in a game. McGonigal (2011) also shared her vision of how games could be used to address climate change, mental wellness, and third world problems. In her book, Reality is Broken, she touched upon the many alternate-reality games that she created in hopes of solving real world problems (for example, EVOKE, World Without Oil, and Superstruct) as well as games that are designed to have positive health impacts and to increase happiness. These include: Top Secret Dance Off, Cruel 2 Be Kind, CryptoZoo, and SuperBetter.

\section{Theoretical Underpinnings of Games for Learning}

Behaviourism as described by Watson (1998) serves as a main theoretical foundation surrounding the impacts of gamification. Behaviourism focuses directly on influences of behaviours based on a stimulus. One classic example is Pavlov's experimentation with dogs where he conditioned a dog to salivate at the sound of a bell as a connection to food; this approach to rewards that stimulate behaviours became known in psychology as operant conditioning. One type of behaviourism specifically connects to the element of 'consequences' in gamification through operant conditioning; when a player has the expectation of a good or bad 
consequence depending on the chosen action, an individual's behaviour changes. Using this notion of operant conditioning, game designers can design game features based on their knowledge that behaviour can be modified when a player understands how consequences happen in a game, regardless of whether they are losses or gains.

Werbach (2013) discussed that the main takeaways from behaviourism that should be applied in gamification consist of observation, feedback loops, and reinforcement. Through observation, we should learn what people do in order to understand consistent patterns that exist. The feedback loop allows a person who has received feedback to use that new knowledge in order to motivate future behaviours. Lastly, learning through reinforcement occurs when a certain action produces a certain result.

Although there are many benefits to behaviourism, there is the danger that design decisions could also lead to abuse or manipulation of individuals within the game environment. For example, although there is an increase in the use of gamification, there is also the argument that games may convince individuals to do things that they would not normally do. Thus, a larger ethical question arises about whether or not the power of games in specific contexts may play a manipulative role. Along those lines, internally, the continuous leveraging of an individuals' reward system could lead to addiction (e.g., slot machines). Another cautionary area is to recognize that once there is a focus on giving people rewards in order to give them pleasure, we must continue to do this or there will not be a continued impact. An individual's interest will decrease if the initial rewards cease or become stagnant.

Another theory that is of interest for gamification focuses on intrinsic and extrinsic motivation and is known as 'Zichermann's SAPS' - an acronym that stands for: status, access, power, and stuff. These factors determine how an individual will experience motivation for any given game. Zichermann and Cunningham (2011) further describe these factors as a hierarchy with status as the highest point. Interestingly, they also say that the lowest point of this set of factors (stuff) is also the most expensive to implement in practice. Therefore, they argue that the focus should be to reach higher and more intrinsically based levels of motivation, with a motivational spectrum ranging from amotivation (no motivation), to extrinsic motivation (being motivated by external factors), to intrinsic motivation (when you are doing something for 
enjoyment). Intrinsic motivation is considered to be the most powerful type based on this spectrum; it connects to self-determination theory (Deci \& Ryan, 2012) and the three factors or aspects of intrinsic motivation including: competence, autonomy, and relatedness. Deci and Ryan (2012) stated that once these three intrinsic motivational factors are realized, individuals will reach their most satisfying result. The realization of the three factors allows individuals to feel passion and excitement during game-play, and this ultimately leads to higher engagement. This unique combination of intrinsic motivational factors that result in such an intense reaction from game players is not normally replicated in real life and more specifically, during learning experiences.

\section{Fun as a Motivator}

The question then becomes: How can this 'fun' experience that game players are intrinsically motivated by, be transferred to other types of environments? When designers ensure that a game is fun by incorporating different types of experiences and challenges, it is likely to engage players. Therefore, in order to be successful in creating a gamification experience, a designer must understand fun and the types of activities that promote the fun in the experience. Lazzaro (2004) discussed her theory in regard to identifying four key types of fun: easy fun, hard fun, serious fun, and people fun. Easy fun is best known as novelty that is incorporated into gameplay. This could encompass player exploration, role play, or creativity. Hard fun is usually experienced in a challenge, when a player achieves a difficult goal. Serious fun is any gameplay that results in meaning making, and people fun is the excitement that comes from the cooperation and competition from playing games with others.

Alternately, LeBlanc, Hunicke, and Zubek (2004) have developed another theory of game fun that describes eight types of fun including: sensation (game as sense-pleasure), fantasy (game as make-believe), narrative (game as drama), challenge (game as obstacle course), fellowship (game as social framework), discovery (game as unchartered territory), expression (game as selfdiscovery), and submission (game as pastime). Regardless of which theory of game fun is adopted, designers should be intentional about incorporating a variety of fun experiences into a game. 


\section{Components, Mechanics, and Dynamics in Game Experiences that are Fun}

When thinking of design elements, it is usually helpful to recognize the components, mechanics, and dynamics that contribute to the overall game experience (Marczewski, 2013). Ways to incorporate fun into a game are just one group of design elements that should be considered in game design. The challenge is to understand when and how to use design elements and to recognize the other design elements that they work in combination with most effectively (if any at all). A main consideration of game designers should be to reflect on the player journey and the emotions that should be evoked during gameplay to optimize the potential of design elements. McGonigal (2011) states that attributes of this journey should include onboarding, scaffolding, and pathways to mastery. Onboarding includes the initial 'training' that a player receives to understand how to play the game. This prepares the player for a role in the game so that less confusion is encountered in the beginning. Scaffolding is a temporary framework incorporated as game players develop, and is then removed once players are able to accomplish certain milestones successfully. By utilizing scaffolding, a player can develop game playing skills through retaining and utilizing previously learned knowledge and skills and being prepared for new challenges throughout the game.

Finally, pathways to mastery allow a player to understand what is required and to know the pathways to achieve success. The player is more likely to experience enjoyable emotions through having a sense of control, supported by clear pathways, during game play. Through implementing these processes, a game designer must remember to think about how to create balance in order to create a game that is not too difficult or too easy, and that uses onboarding, scaffolding, and pathways to mastery in optimal ways.

\section{Design Thinking}

Design thinking challenges designers to be both analytical and creative, and game designers must find the appropriate balance between these. Werbach and Hunter (2012) have established a 6-step process for a gamification design framework, including:

1. Define business objectives - What are the goals of this initiative?

2. Delineate target behaviour - What end result should players experience?

3. Describe your players - Who are the individuals playing the game? 
A Meta-Synthesis

4. Devise activity loops - How will the action move forward in the game?

5. Don't forget the fun - How will game design thinking and fun be incorporated into the design?

6. Deploy the appropriate tools - What design tools and techniques will be used?

A useful tool that was introduced by Kapp (2012) matches the type of knowledge that a designer is hoping to 'teach', with the game elements that could be utilized to foster that knowledge (see also Werbach and Hunter, 2012). The knowledge categories identified by Werbach and Hunter includes: declarative, conceptual, rules-based, procedural, problem-solving, soft skills (e.g., negotiation, leadership, selling), and affective skills. The application of design thinking, aligned to the knowledge categories that define the goal of the game, allows game design to remain intentional. Well-thought out structures provide us with the foundation to apply gamification in the educational context.

\section{Emotions and Gameplay}

Fiero is an emotion that is evoked through game play and which many individuals might agree is difficult to experience in daily life:

...fiero is the Italian word for "pride", and it's been adopted by game designers to describe an emotional high we don't have a good word for in English. Fiero is what we feel after we triumph over adversity. You know it when you feel it - and when you see it. That's because we almost all express fiero in exactly the same way: we throw our arms over our head and yell. (McGonigal, 2011, p. 33)

Eustress is another player experience that is best described as hard fun:

... during eustress (...) we've generated the stressful situation on purpose, so we're confident and optimistic. As long as we feel capable of meeting the challenge, we report being highly motivated, extremely interested, and positively engaged by stressful situations. And these are the key emotional states that correspond with overall well-being and life satisfaction. (McGonigal, 2011, p. 32) 
Fiero and eustress need to be built into educational games by design. Games also impact us by inspiring flow that is described as, "the satisfying, exhilarating, feeling of creative accomplishment and heightened functioning” (McGonigal, 2011, p. 35). Getzels and Csikszentmihalyi (1976) first used the term "flow" to describe this type of gameplay response; their studies state that there is a lack of flow in everyday life, but where flow does appear time and time again, is in games. Additionally, McGonigal's (2011) research described how flow is most reliably produced by the combination of personally optimized obstacles, self-chosen goals, and continuous feedback, all of which can be intentionally included in game designs.

\section{Gamification in Education}

In the higher education environment, more often than not, the delivery structure of information is lecture-style based. Bloom (1953) found that, "during lectures, students' thoughts involved attempting to solve problems, or synthesize, or inter-relate information for only one percent of the time, while 78 percent of the lecture was spent in passive thoughts about the subject and irrelevant thoughts" (Kapp, Blair, \& Mesch, 2014, p. 122). Similarly, researchers Kapp et al. (2014) stated, "Lectures are not a very effective way of teaching in higher education - especially if the aim is to teach thinking, or to change attitudes or other higher aims beyond the simple transmission of factual knowledge" (p. 122). A conclusion that can be drawn from this information is that, lecture-based learning is not always a reliable method for knowledge acquisition and/or student engagement, and thus may be a method of learning that is not useful in a co-curricular gamification initiative. This analysis supports a conclusion that stronger instructional methods, including gamification, within the education environment, should be explored.

According to a research study by Blunt (2007), the mean scores of students in classes using game-based learning (i.e., video games) were significantly higher than those of students in classes that did not use this strategy. Connolly, Boyle, Boyle, MacArthur, and Hainey (2012) completed a meta-analysis on gamification and discovered that the majority of the studies shared one strong conclusion: that the most "frequently occurring outcomes and impacts [of the use of gamification] were knowledge acquisition/content understanding and affective and motivational outcomes" (p. 59). With the lens of offering opportunities for students that are focused on 
personal and professional development within a higher education and volunteer environment, it leads to the conclusion that there could be benefits to exploring an innovative method of organizing the learning that is occurring in co-curricular experiences.

The increase in research being published on gamification in education has grown from 2011 to the present. Caponetto, Earp, and Ott (2014) demonstrate how quickly the popularity of gamification is rising and how more publications about the concept are being released each year within the academic environment. Caponetto et al. (2014) also note that 7\% out of 119 papers that were examined for their study are Canadian-based research. Gamification impact is clearly a topic of international research, as there were over 25 countries represented in this study. Also, this study found that $43 \%$ of gamification used in education was in the higher education environment, specifically, in university courses.

\section{Research Goals}

The purpose of this meta-synthesis was to examine the elements of strong game design in gamification initiatives related to educational goals. With a clear model for effective gamification established by the meta-synthesis, it was hoped that the model could then be applied to the design of a gamified volunteer initiative in a higher education volunteer program.

\section{Methods}

Within the process of locating which literature could be utilized in this meta-synthesis, several key sources were located. The first method of research was searching via the University of Toronto's online library database, beginning with general and broad keywords such as 'gamification' then, narrowing search results through inputting different keyword searches that included the following: studies on gamification, gamification in higher education, and gamification in student affairs. When determining which articles to utilize, the focus was on studies in the higher education environment. Although there was a scarcity of articles that were specific to student affairs, there were a variety of studies that had been conducted within academic classrooms in higher education. Similarly, studies that focused specifically on motivation, engagement, volunteer programs, and professional development, whether inside or outside of the higher education environment, were selected, as this parameter would be relatable 
to the main topic of the meta-synthesis. Additionally, experts in gamification were consulted and existing literature reviews were analyzed to isolate the most informative research.

\section{Meta-synthesis vs. Literature Review}

In the initial development of information in a meta-synthesis, one might easily mistake it for a literature review. However, these two processes are different and unique. While a literature review may offer an overview of research in a particular field, it does not function to provide its audience with an adequate critical examination of research that would allow for a new perspective or research direction. This difference is elaborated by Sandelowski, Docherty, and Emden (1997), where they discuss how, "a qualitative meta-synthesis is not about averaging or reducing findings to a "common metric" (Wolf, 1986, p. 33), but rather enlarging the interpretive possibilities of findings and constructing larger narratives or general theories” (p. 369).

The meta-synthesis approach allows a researcher to think critically about how the integration of this new data may occur. This eliminates the potentially costly repetition of a new study when there is substantial information already available that has yet to be analyzed for patterns and new perspectives. Such an approach to knowledge construction provides us with stronger generalizations about a body of subject matter, as well as access to the limits of these generalizations. Cooper, Hedges, and Valentine (2009) describe how a meta-synthesis pays attention to relevant theories, critically analyzes the research they cover, resolves conflicts in the existing literature, and attempts to identify central issues for future research. There is a sense of novelty that should be delivered in a meta-synthesis, as the hope is to create a new idea or understanding that will potentially be implemented in future research. This sense of novelty is a primary difference between meta-synthesis and a literature review (Cooper, Hedges, \& Valentine, 2009).

In order to conduct an appropriate meta-synthesis, there are a number of basic proposed guidelines that one should follow. While this research methodology is not as structured as others, there are still some best practices that should be noted before the implementation of a metasynthesis begins. Cooper et al. (2009) outline these steps (pp. 11-14):

\section{Problem Formulation}


A Meta-Synthesis
2. Literature Search
3. Data Evaluation
4. Data Analysis
5. Interpretation

\section{Strengths and Weaknesses of a Meta-synthesis}

Like any research methodology, there are both strengths and weaknesses in choosing to explore a topic with meta-synthesis. There is the initial sense on one end of the spectrum that, "even the thought of synthesizing qualitative research findings violates the assumptions and imperatives of qualitative research" (Sandelowski et al., 1997, p. 366). To elaborate on this, there is worry that the level of detail of human experiences normally included in qualitative studies will be lost through the attempt to combine and synthesize studies, as this may sacrifice the integrity of the final findings. Another concern is the struggle with identifying the criteria that constitute a good and reasonable study to use (Sandelowski et al., 1997, p. 367).

A way to address these concerns is to be vigilant with applying selection criteria when determing the studies that will be analyzed throughout the meta-synthesis. Factors that were considered throughout choosing the meta-synthesis studies included:

- Was it a qualitative or quantitative example?

- Was it written post 2010?

- Is this an example of gamification or game-based learning?

- Are there examples that include factors of personality types in gamification?

- Are there examples that include only one game mechanic/dynamic being utilized?

- Are there examples where more than one game mechanic/dynamic is utilized?

- Is there an example that discusses gamification and volunteers?

- Are there successful examples of gamification?

- Are there non-successful examples of gamification?

- Is the main demographic young adults (preferably in the higher education environment)?

- Was the methodology sound?

- Where was the research completed? 
Another strategy involves complete check-ins with the material that is being written to ensure close reference to the original documents before the final product is released.

Some other areas of weakness in meta-synthetic strategies that have been brought to the forefront by many researchers are the gaps in certain areas of a meta-synthesis. These gaps potentially include weaknesses such as: reaching consensus on a common terminology for what this area of research should be named; whether to integrate the information with the same method as utilized in the primary study; how to conduct qualitative research syntheses; and what the goal of a qualitative research synthesis should be (Noblit \& Hare, 1988; Thorne, Jensen, Kearney, Noblit, \& Sandelowski, 2004).

These are concerns that have been addressed by a variety of researchers and there have been a number of suggestions made in regard to ways to overcome these potential obstacles. One of the main areas of weakness in a meta-synthesis is in the coding process. The amount of error that may enter a synthesis during coding are addressed through three major approaches, including: "measuring inter-rater agreement, obtaining confidence ratings from coders, and conducting sensitivity analysis or using multiple coding strategies to determine whether a synthesis' conclusions are robust across different coding decision rules" (Cooper, Hedges, \& Valentine, 2009, p. 13).

Continued transparency throughout this process was significant to the success and weight of this meta-synthesis. By following through in taking precautions, such as describing how research studies were located and why specific studies were chosen, a solid methodology can be accomplished. Through the creation of such processes, any potential concerns that the studies were specifically chosen to skew results were decreased or completely eliminated.

The lack of standard terminology and standardized procedures could be considered to be strengths of meta-synthesis, in that these allow for freedom and flexibility throughout the selection process. Additionally, sometimes adding more research to the field can be time consuming and costly and may not be required. Making use of other research from different areas will allow amalgamation of the lessons learned and create a high quality gamification initiative that would be appropriate for student affairs. This meta-synthesis will hopefully assist 
in providing a general structure for other higher education professionals when creating a gamification initiative. A certain level of consistency would take place in order to assess whether gamification should be applied in co-curricular environments to yield successful results.

Meta-synthesis also seems like a suitable method to examine the literature about gamification, as it is a fairly new topic of interest and the research in this field is continuing to grow. Another positive aspect of a meta-synthesis is that it captures the importance of qualitative research. Qualitative synthesis can enhance the "power" (Kearney, 1998, p. 182) and "utilization value" (Smaling, 2003, pp. 20-21) of qualitative research findings.

Key considerations such as the inclusion of a mix of qualitative and quantitative studies and studies in the Canadian context of gamification were study filters. There was a lack of Canadian representation in the research literature resulting in only one study included in this analysis being from a Canadian institution, and it was not specific to a higher education environment. Lastly, through using the online search tool in the University of Toronto database, specific filters were applied to locate studies written in English with research publication dates after 2010 .

Using these approaches and criteria for selecting studies for the meta-syntheses, 29 studies were selected for analysis.

\section{Results}

It was evident from this meta-synthesis that, while many of the elements of creating successful gamified experiences may be known from previous theories and from studies of successful gaming designs and their impact, many questions still remain about how all of the elements of strong game design function in relation to learning. How the various game elements work together, when they should most effectively be used, and the types of learning they should most effectively address, along with who might benefit most from the combinations of choices that a game design builds into the gamification experience, present a complex series of interwoven choices for designers. 
A Meta-Synthesis

The complexity of these choices is presented in Figure 1. This figure has been designed to show graphically the range of proven effective approaches that have been identified through this meta-synthesis. This graphic represents a set of recommendations based on the research and literature examined throughout the meta-synthesis that would allow an individual to create and apply a gamification initiative within a co-curricular experience in a higher education environment. 


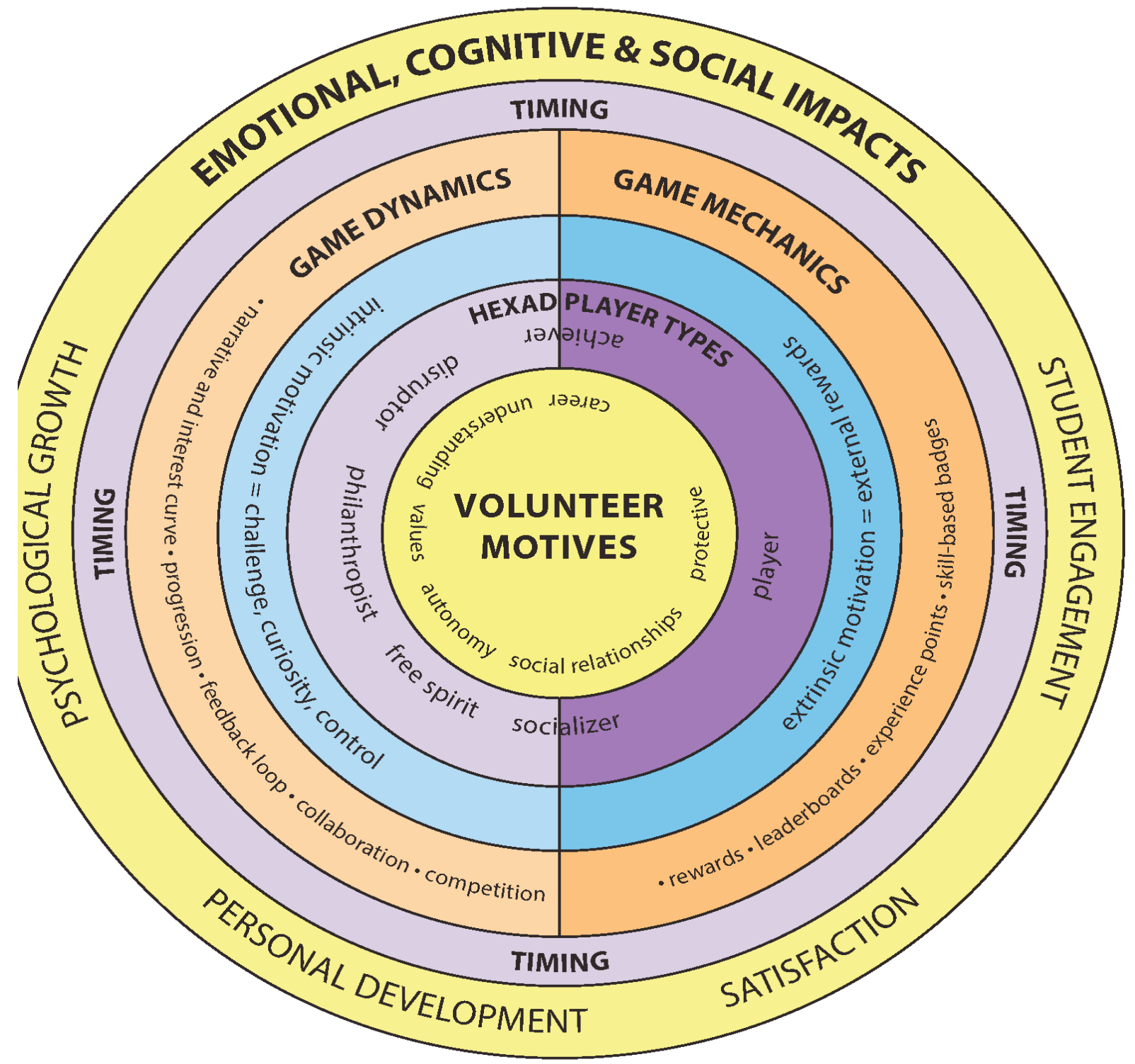

ADDITIONAL STRUCTURAL GAMIFICATION CONSIDERATIONS:

- target skill definition

- pre-determination of player types

- reflective of foundational theories, self-determination theory, self-efficacy, etc.

- alignment of knowledge types and gamification elements
- options for participation

- appeals to various player types

- consistency across play platforms

- a combination of multiple game mechanics and dynamics

- usability
- in-depth player feedback process assessment

- user demographics

- linear/non-linear progression

- social engagement loops

- onboarding

- an appropriate online platform

Figure 1 A model for gamification design choices in a co-curricular volunteer environment 
The diagram highlights the relationships among the various considerations of game design. In the diagram, the central section illustrates the various motives that might be engaging to possible individuals participating in the volunteer gamified environment. By following the rings adjacent to the various motives, one can identify the game dynamics or game mechanics (shown in the orange ring) that promote that type of engagement and learning most appropriate for that participant. For example, volunteers who are motivated by enhancing understanding may exhibit more personality traits of those players (shown in the light purple ring of HEXAD PLAYER TYPES (Marczewski, 2013) who are influenced by intrinsic motivation (the blue ring) and game elements such as narratives, feedback loops, and competition or collaboration (the orange ring). On the other hand, volunteers who are motivated by social relationships or career enhancement may exhibit the personality traits of a socializer, player, or achiever and be more motivated by extrinsic motivators, such as the game mechanics of leaderboards and experience points. A quality game design will incorporate aspects of game mechanics and game dynamics that engage all of the personality types. At minimum, the recommendation would be to utilize the listed game dynamics and game mechanics for a comprehensive gamification experience within a co-curricular environment, to satisfy the motives of each gamification personality type and design approaches that could be applied to ensure the experience is fun.

Therefore, Figure 1 proposes a structure and framework of the types of considerations that influence intentional gamification of a co-curricular volunteer experience. While the focus is on volunteers, this model could certainly be expanded and applied to other types of co-curricular programs on campus. This study also provides a pathway for future research to be conducted by using this model to implement the recommendations and assess the impact of gamification accurately. These suggestions encourage the use of gamification in environments where the outcomes include professional development, student engagement, and participation.

A main obstacle with the existing literature on gamification is that it appears that many of the existing gamification structures only utilize extrinsic motivators and that there still remain Hexad player types (i.e., free spirit, disruptor, philanthropist, disruptor) who may not necessarily be motivated by these game mechanics. When developing a gamification program, game dynamics and mechanics should work together so that an individual can witness a streamlined experience. 
Another important piece that ties this concept together is timing and intentionality of when certain game mechanics and game dynamics can take place. This ties into game dynamic ideas such as progression and the creation of a well-thought out narrative with an interest curve.

Below the graphic is a summary of additional considerations that were discovered throughout this meta-synthesis that should be recognized for the proposed successful creation and structuring of a gamification initiative. When all of these elements are intentional and appropriately implemented, this meta-synthesis proposes emotional, cognitive, and social impacts, such as student engagement, psychological growth, personal development, and satisfaction. A summary of the proposed additional gamification structural considerations for a co-curricular experience include the following items:

- Defining what skills should be developed through the implementation of a gamification program by creating learning outcomes and goals;

- Determining player types beforehand by completing a user personality type test;

- Providing options and allowing the freedom to choose how a student would like to participate in the program;

- Ensuring that there are activities that would appeal to the player types of philanthropist, socializer, free spirit, achiever, player, and disruptor;

- Ensuring consistency between online systems and in-person gamified experiences and when possible, using a mixture of both platforms;

- Utilizing the proposed game mechanics that are intentionally crafted based on existing research on what has and has not worked. Each game mechanic that is implemented should have a purpose and be unique. The more well-thought out game mechanics can be, the easier they can be implemented, and achieve a higher likelihood of success;

- Incorporating a thorough assessment and onboarding process;

- Recalling foundational theories such as self-determination and intrinsic and extrinsic motivation and making sure that these concepts are applied;

- Determining an appropriate online platform;

- Aligning the development of knowledge type to the appropriate gamification element;

- Ensuring that the gamification initiative is not rushed in its creation and is implemented for students to ensure that it is well received. Students should have a full understanding 
on how to navigate the gamification experience before beginning any research into program impacts. Plans of action should be put into place in order to mitigate student confusion;

- Remembering that gamification must be creative and must appeal to the demographic of its learners; and

- Implementing an in-depth feedback process before the creation of a gamification program can take place.

\section{Implications}

This research project proposes that the combination of correctly utilizing a variety of game dynamics and mechanics, while also aligning them with the variety of player types, truly provides a foundation to assess the impact of gamification properly. Additionally, this research has shown that trying to focus on assessing one game mechanic or dynamic at a time is not a successful way to conduct research on a gamification initiative, as these elements should work together in order for a gamification program to be created successfully. Furthermore, gamification needs to be intentional and well-thought out. This is a focus that is sometimes missing in the existing literature.

Based on the findings of this meta-synthesis, a list of recommendations has been summarized and is displayed in Table 1. This table provides examples about how each facet of design could be applied to a higher education volunteer program, specifically, the Orientation Ambassador role at the University of Toronto, Mississauga (UTM).

Table 1. Applying gamification research to inform the design of the Orientation Ambassador Program at UTM

\begin{tabular}{ll}
\hline Research Finding & How it could be applied \\
Points & This mechanic would be implemented through 'experience points'. \\
& Participation in different activities should be tied into points. Points can be \\
traded in for 'individual rewards' and 'team rewards' at the end of the year. & An example of this could be: \\
& 4 hour Orientation shift $=60$ points \\
& 1 hour team meeting $=15$ points \\
\hline
\end{tabular}


Rewards

Badges

Leaderboards

Narrative

Levels

Collaboration/

Social

Engagement

Feedback
- Points can be traded in for 'individual rewards' such as once a student reaches a certain amount of points, the supervisor would be a reference for that student if asked.

- Creation of skill-based badges (that align with the competencies) that students will receive for CCR recognition. This would match well with a student's interest and act as a stronger motivator for students to want to participate in different volunteer activities. Badges could correspond with certain tasks or activities based on the competencies they would be fostering in each experience. Therefore, when a student signs up for an activity they would be able to see what competencies they were developing through the activity.

- The best way to track the accumulation of the badges would be with an online system.

- Provide students the option of displaying their badges on their online profile (private, semi-private, or public).

- Create an anonymous leaderboard or 'player name'.

- Generate a weekly random ranking list to be distributed by email.

- Create a Facebook group to communicate; create and post a weekly graphic that summarizes the weekly standings. Another option would be to find an online platform that contains this feature.

- $\quad$ Every year a group of interested ambassadors will work with a paid student staff leader (work-study position) to create the story for the following year.

- The story pieces will be delivered via a weekly email. The story that will take place will always by a mystery that needs to be solved. Additional points will be rewarded for students who interact with the game and participate in a weekly 'challenge' test embedded in the email that will ask questions that link to the narrative as well as to a student's learning.

- The story is to include an interest curve.

- There would be different levels that could be 'unlocked' based on a student's successful completion of the narrative challenges.

- Bonus points will be rewarded for individuals who participate in positive recognition initiatives within the team or extended to other teams.

- One-on-one mentor meetings will allow a student to reflect on growth of their current skill set and to set goals to revisit throughout their ambassador experience.

- Reflection logs should be completed at the end of each term for students to 
reflect on the skills they have developed through their experiences and any learning that has occurred.

Progression

Personality

Preferences

The Hexad

Model

Student

Demographics
- Learning outcomes for the Orientation and Outreach program are as follows:

By the end of the Orientation and Outreach Ambassador program, students will:

- improve their self-awareness;

- be able to complete with confidence socially intelligent conversations with other UTM students;

- be able to demonstrate teamwork;

- be able to carry out the successful completion of the program through goal-setting and prioritization; and

- be able to practice communication skills in context.

- Use an anonymous suggestion box (online) where students are able to elaborate if a certain gamified addition is not working for them.

- Include assessment measures for students to reflect on their experiences and needs.

- Before a student begins the Orientation and the Outreach Ambassador role, he/she would take a Hexad Model quiz to outline what his/her player type is. A student can receive a personalized 'handout' as to recommended 'experiences' that may appeal and why, as well as suggestions as to how they can motivate themselves throughout the experience.

- Instead of consistent weekly meetings, consider alternative methods for students who may be unable to attend, such as webinar meetings. Finding a time that works well for such a large number of commuter students would certainly create a barrier in having full attendance for on-site meetings.

- Utilize online modules for training needs where possible.

\section{Discussion}

This research has presented new ideas regarding the range of impacts that gamification can have in the higher education environment. While historically gamification has been relied on heavily for the improvement of knowledge retention in formal education, this meta-synthesis suggests that applying this concept to co-curricular experiences, in order to increase engagement and the professional development of students on campus, may have positive benefits. The topic of utilizing gamification in a co-curricular experience has not yet been explored; the current existing research draws heavily on formal education environments. Furthermore, conducting this 
type of research in the Canadian context could potentially yield new results, as based on the research conducted through this meta-synthesis, there is currently a lack of gamification research in Canada.

Based on the research that was analyzed in this study, gamification does not yet have a consistent foundation that can be utilized in various situations and appropriately measured. Thus, comparisons between gamification results became quite difficult to determine and measure.

Figure 1 provided a model for consistent structure that can be utilized in the creation of gamification initiatives within co-curricular experiences. With the proposed structure, it could become easier to assess whether or not gamification can yield successful outcomes within the higher education environment, when it is intentional and research-based.

Laura Mammone completed her Masters of Education at the Schulich School of Education at Nipissing University in North Bay, Ontario. Her career background includes working in the higher education environment for the past nine years in areas such as residence life and student affairs. Her research interests include professional growth, program development, and curriculum development.

Dr. Nancy Maynes is a Full Professor in the Schulich School of Education at Nipissing University. Her research interests include teacher education and professional growth, specifically aspects of teacher education that influence strategy efficacy, service learning, professional reflection, the internalization of key curriculum concepts, and teacher hiring practices.

\section{References}

Bloom, B. S. (1953). Thought processes in lectures and discussions. Journal of General Education, 7(3), 160-169.

Blunt, R. (2007). Does game-based learning work? Results from three recent studies. In proceedings of Interservice/Industry Training, Simulation, \& Education Conference. Orlando, FL: NTSA.

Caponetto, I., Earp, J., \& Ott, M. (2014). Gamification and education: A literature review. Paper presented at the European Conference on Game Based Learning, 1 50-57. Retrieved from https://pdfs.semanticscholar.org/2b9b/64350c1d2d6f9103b8505612e98afb1da3bb.pdf

Connolly, T., Boyle, E., Boyle, J., MacArthur, E., \& Hainey, T. (2012). A systematic literature review of empirical evidence on computer games and serious games. Computers and Education, 59, 661-686. Retrieved from https://www.cs.auckland.ac.nz/courses/compsci747s2c/lectures/paul/LitReview_Empirica Evidence SeriousGames.pdf

Cooper, H., Hedges, L., \& Valentine, J. (2009). The handbook of research synthesis and meta-analysis. New York: Russell Sage Foundation. 
Deci, E. L., \& Ryan, R. M. (2012). Motivation, personality, and development within embedded social contexts: An overview of self-determination theory. In R. M. Ryan (Ed.), Oxford Handbook of Human Motivation (pp. 85-107). Oxford, UK: Oxford University Press.

Dominguez, A., Saenz-de-Navarrete, J., De-Marcos, L., Fernandez-Sanz, L., Pages, C. \& Martinze-Herraiz, J-J. (2013). Gamifying learning experiences: Practical implications and outcomes. Computers \& Education, 63, 380-392.

Evans, J. N., Forney, S. D., Guido, M. F., Patton, D. L., \& Renn, A. K. (2010). Student development in college: Theory, research, and practice. San Francisco, CA: JosseyBass.

Gee, J. P. (2003). What video games have to teach us about learning and literacy. New York: Palgrave Macmillan.

Getzels, J. W., \& Csikszentmihalyi, M. (1976). The creative vision. New York, NY: John Wiley \& Sons.

Kapp, K. M. (2012, June 8). Games, gamification, and the quest for learner engagement. Retrieved from https://www.td.org/Publications/Magazines/TD/TDArchive/2012/06/Games-Gamification-and-the-Quest-for-Learner-Engagement

Kapp, K. M., Blair, L., \& Mesch, R. (2014). The gamification of learning and instruction: Ideas into Practice. San Francisco, CA: Wiley.

Kearney, M. H. (1998). Ready-to-wear: Discovering grounded formal theory. Research in Nursing \& Health, 21(2), 179-186.

Lazzaro, N. (2004). Why we play games: Four keys to more emotion. Paper presented at the Game Developers Conference, San Jose, California.

LeBlanc, M., Hunicke, R., \& Zubek, R. (2004). Mechanics, dynamics, aesthetics: A formal approach to game design. Paper presented at Game Developers' Conference, San Jose, California.

Marczewski, A. (2013, June 5). Gamification user types and the 4 keys 2 fun [blog post]. Retrieved from http://www.gamified.uk/2013/06/05/gamification-user-types-and-the-4keys-2-fun/

Maslow, A. H. (1943). A theory of human motivation. Psychological Review, 50(4), 37096.

Malone, T. W. (1980). What makes things fun to learn? Heuristics for designing instructional computer games. ACM Computing Literature, Symposium on Small Systems. Proceedings of the 3rd ACM SIGSMALL. Retrieved from https://www.hcs64.com/files/tm\%20study\%20144.pdf .

McGonigal, J. (2011). Reality is broken: Why games make us better and how they can change the world. New York, NY: The Penguin Press.

Noblit, G., \& Hare, R. D. (1988). Meta-ethnography: Synthesizing qualitative studies. London: Sage.

Sandelowski, M., Docherty, S., \& Emden, C. (1997). Focus on qualitative methods qualitative metasynthesis: Issues and techniques. Research in Nursing \& Health, 20, 365-371.

Sanford, N. (1966). Self and society: Social change and individual development. New York, NY: Atherton Press.

Schell, J. (2008). The art of game design. New York, NY: Elsevier Inc.

Smaling, A. (2003). Inductive, analogical, and communicative generalization. International 
Journal of Qualitative Methods, 2(1). Retrieved from https://sites.ualberta.ca/ iiqm/backissues/2 1/pdf/smaling.pdf

Thorne, S., Jensen, L., Kearney, M. H., Noblit, G., \& Sandelowski, M. (2004).

Qualitative metasynthesis: Reflections on methodological orientation and ideological agenda. Qualitative Health Research, 13, 1-24. http://dx.doi.org/10.1177/1049732304269888

Watson, J. (1998). Behaviorism. New York, NY: Routledge. https://doi.org/10.4324/9781351314329

Werbach, K. (2013). Gamification. Coursera [online]. https://www.coursera.org/learn/gamification\#

Werbach, K., \& Hunter, D. (2012). For the win: How game thinking can revolutionize your business. Philadelphia, PA: Wharton Digital Press.

Wolf, F. M. (1986). Meta-analysis: Quantitative methods for research synthesis. Newbury Park, CA: SAGE Publications Inc.

Zichermann, G., \& Cunningham, C. (2011). Gamification by design: Implementing game mechanics in web and mobile apps. Sebastopol, CA: O'Reilly Media. 